\title{
地震動を単純化するための正弦波形抽出方法
}

\section{EXTRACTION METHOD OF SINUSOIDAL WAVES FROM EARTHQUAKE GROUND MOTION TO SIMPLIFY THE MOTION}

\author{
山本雅史 ${ }^{*}$, 佐藤 吉之**, 井上修作 ${ }^{* * *}$ \\ Masashi YAMAMOTO, Yoshiyuki SATO and Shusaku INOUE
}

\begin{abstract}
A simplification method of earthquake ground motion using sinusoidal waves is proposed. The method has the advantages of wavelet analysis, suitable for non-stationary states, and Fourier analysis, suitable for stationary states, through extracting the best-matched waveforms using multiple wavelets. The proposed method was formulated and applied to an acceleration waveform observed in the 1995 Kobe earthquake in addition to a frequency-swept sinusoidal waveform. The results showed the method appropriately extracted both non-stationary and stationary waveforms. This method could be utilized to resolve a waveform into various waveform components caused by different propagation paths.
\end{abstract}

Keywords: Earthquake ground motion, Wavelet analysis, Fourier analysis, Extraction method, Simplification 地震動, ウェーブレット解析, フーリエ解析, 抽出方法, 単純化

\section{1.はじめに}

内陸地殼内地震の震源近傍でパルス性の地震動が観測されている。 この地震動は免震建物や超高層建物に大きな影響を与える可能性が 指摘され、近年多くの研究が行われている。その基本的な検討を行 うために地震動を単純化する研究 ${ }^{1)}{ }^{-3)}$ がなされている。Baker ${ }^{1)}$ は ウェーブレット解析により観測地震波形からパルス波形を抽出する ことを提案した。Baker はウェーブレットとして Daubechies wavelet(4 次)を用い、速度波形に対して抽出を行っている。Vassiliou and Makris ${ }^{2)}$ は Ricker 波およびその微分に加え、正弦波に基づく複 数のウェーブレットを用い、加速度波形に対する抽出を行い、抽出 時の重み関数の影響なども含めて検討を行った。小山・永野 ${ }^{3)}$ は Sin 波、Ricker 波およびその微分、Daubechies wavelet(4 次) およびそ の微分を用い、疑似速度スペクトル（減衰 5\%）价観測波形による ものと近くなるよう単純化した。

このような単純化されたパルス波を用いて、例えば、正弦波パル スによる免震建物の検討 ${ }^{4)}$ や Ricker 波を用いた超高層建物の検討 ${ }^{5)}$ 、

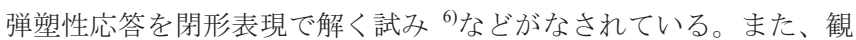
測地震波形の単純化は、地震動がパルス性かどうかの指標としての 利用や、複数の観測地震波形から震源モデルを検討する際の手法例え ば7としての利用が考えられ、地震波形の単純化は重要な課題である といえる。

従来、波形解析は周期、振幅、位相の観点から様々な適用が図ら
れており、単純化された波形を有効に利用するためにも、その波形 の周期、振幅、位相が明確に定義されている必要があると筆者らは 考える。このため本研究では、周期、振幅、位相が明確に定義され た波形を要素波形とし、少ない数の要素波形で地震波形を単純化す ることを目的とする。

既往の研究で抽出に用いる手法は、ウェーブレット解析に基づく が、ウェーブレットとしてよく用いられる Ricker 波、Daubechies wavelet など周期、振幅が明確に定義されていないものが多い。また、 これらのウェーブレットは位相を任意に設定できない。Vassiliou and Makris では正弦波に時系列のフィルタ（Gaussian または Cosine）を かけることで任意の位相を扱えるパルス波も紹介されているが、こ れらのフィルタは正弦波に対して常に振幅や周期を変化させる。な お、ウェーブレット解析では、基になるウェーブレットは全区間の 積分值が 0 になることが必要条件になる。しかし、前述の Vassiliou and Makris のウェーブレットは積分值が 0 にならないためそのまま 使えず、微分したものをウェーブレットとして用いている。この微 分により周期・振幅の定義は更に不明確になる。

本論文では前述の目的のため、周期、振幅、位相が正弦波との関 係で明確に定義され、かつ積分值が 0 になる（ウェーブレット解析 の必要条件を満足する）ウェーブレット群を提案する。さらに提案 したウェーブレット群の中から元の波形との残差の二乗和が最も小 さくなるウェーブレットを決定し、その周期、振幅、位相を算出す

\footnotetext{
* 竹中工務店技術研究所 地震工学部長 · 博士 (工学)

** 竹中工務店技術研究所 地震動グループ長・修士 (理学)

*** 竹中工務店技術研究所 主任研究員 ·博士 (工学)
}

General Manager, Research and Development Institute, Takenaka Corporation, Dr.Eng. Group Leader, Research and Development Institute, Takenaka Corporation, M.Sc.

Chief Researcher, Research and Development Institute, Takenaka Corporation, Dr.Eng. 
る方法について述べる。通常のウェーブレット解析では非定常性の 強い 1 つのウェーブレットに対して適合性の高い波形を抽出するが、 本提案手法では非定常性の強いものから定常性の強いものまで複数 のウェーブレットに対し、最適なものを抽出可能とする。このため、 通常のウェーブレット解析では抽出されない定常的な要素波形も抽 出される。

\section{2. ウェーブレット群}

提案するウェーブレット（群）は周期、振幅、位相の定義を明確 にするため、正弦波に時系列フィルタをかけて作成する。Fig.1 はそ の概念を示したもので、周期 $2 \pi$ 、振幅 1 のウェーブレット $\psi_{\alpha}$ が正 弦波 $\sin (t+\alpha)$ と時系列フィルタ $\xi(t)$ の積で表されている。

$$
\psi_{\alpha}(t)=\xi(t) \sin (t+\alpha)
$$

ここで、 $t$ は時刻、 $\alpha$ は任意の位相を与えるためのパラメータである。 また、時系列フィルタは以下のように設定する。

$$
\begin{aligned}
& \xi(t)=\zeta(-t-\pi / 2) \quad t<-\pi / 2 \\
& \xi(t)=1 \quad-\pi / 2 \leq t \leq \pi / 2 \\
& \xi(t)=\zeta(t-\pi / 2) \quad \pi / 2<t
\end{aligned}
$$

ここで、らはカットオフ領域の形状を決定する関数である。Fig.1 お よび式(2b)に示す通り、 $\xi$ は $\pi / 2 \leq t \leq \pi / 2$ の領域において 1 とな るため、同領域ではウェーブレット $\psi_{\alpha}$ は完全に正弦波と一致し、ウ エーブレットにおける周期、振幅、位相の意味づけが明確である。

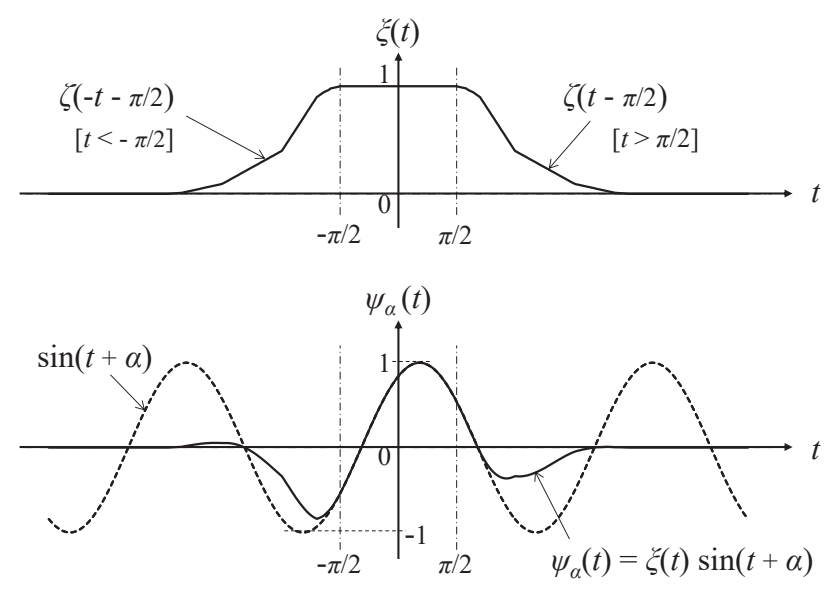

Fig.1 Concept of proposed wavelet

ウェーブレット解析の必要条件としてウェーブレットはその全区 間における積分值が 0 である必要がある。すなおち、

$$
\int_{-\infty}^{\infty} \psi_{\alpha}(t) d t=0
$$

式(3)を展開すると、

$$
\begin{aligned}
\int_{-\infty}^{\infty} \psi_{\alpha}(t) d t & =\int_{-\infty}^{\infty} \xi(t) \sin (t+\alpha) d t \\
= & \int_{-\infty}^{-\pi / 2} \zeta(-t-\pi / 2) \sin (t+\alpha) d t+\int_{-\pi / 2}^{\pi / 2} \sin (t+\alpha) d t \\
& \quad+\int_{\pi / 2}^{\infty} \zeta(t-\pi / 2) \sin (t+\alpha) d t \\
= & \int_{\pi / 2}^{\infty} \zeta(t-\pi / 2)\{\sin (t+\alpha) d t+\sin (-t+\alpha)\} d t+2 \sin \alpha
\end{aligned}
$$

$$
=2 \sin \alpha \int_{\pi / 2}^{\infty} \zeta(t-\pi / 2) \cos (t) d t+2 \sin \alpha=0
$$

従って、 $\sin \alpha \neq 0$ に対しても上式を成立させるためには、

$$
\int_{\pi / 2}^{\infty} \zeta(t-\pi / 2) \cos (t) d t=-1
$$

すなわち、

$$
\int_{0}^{\infty} \zeta(t) \sin (t) d t=1
$$

フィルタを決定する関数 らは式(6)を満足する必要がある。このよ うならは無数に存在する。例えば、式(6)を満足し、かつ、そおよび $d \xi / d t$ が連続となる関数として、下式がある。

$$
\begin{array}{ll}
\zeta(t)=(\cos (t /(2 N+1))+1) / 2 & 0 \leq t \leq(2 N+1) \pi \\
\zeta(t)=0 & (2 N+1) \pi<t
\end{array}
$$

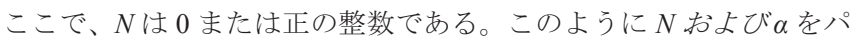
ラメータとして、同じ関数で表現できる複数のウェーブレットが得 られた。この集合をウェーブレット群と称する。以降の検討は、式

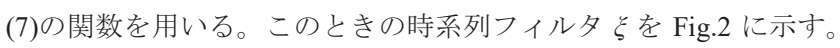
また、このフィルタにより作成されるウェーブレットについて $N=0$ および $N=1$ の例を $\alpha=0, \pi / 4, \pi / 2,3 \pi / 4$ の各位相に対して Fig.3に示す。

本抽出法は主に加速度に対して用いることを想定している。本ウ エーブレットを加速度とすれば、その積分值が速度 $V$ 、更にその積 分值が変位 $D$ を表す。速度について Fig.4 に、変位について Fig.5 にそれぞれ $N=0$ および $N=1$ の例を示す。ウェーブレットの条件とし て式(3)を課しているので、Fig.4 に示す速度は $N 、 \alpha$ にかかわらず最 終的に 0 になる。一方、変位は、 $N=1$ の場合は最終的に 0 になるが、 $N=0$ の場合は $\alpha=\pi / 2$ のケースを除いて最終的に 0 にならず、残留変

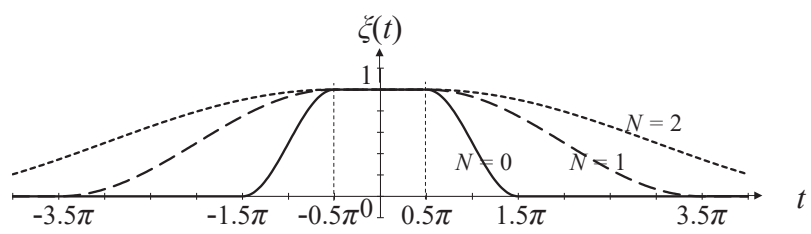

Fig.2 Time-domain filter

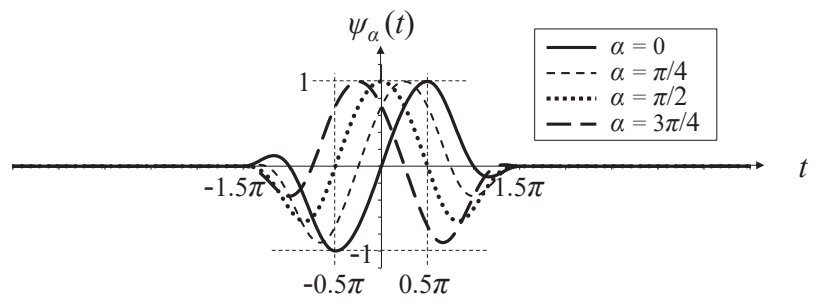

(a) $N=0$

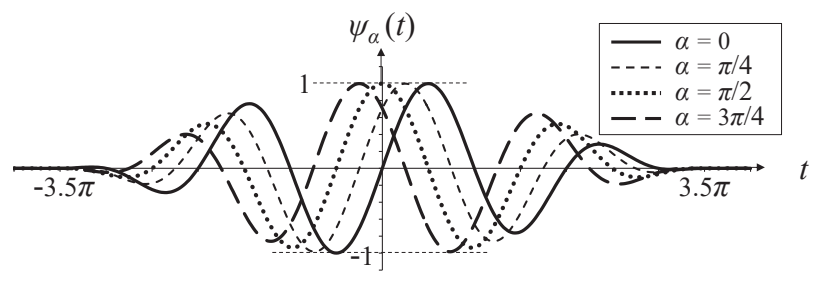

(b) $N=1$

Fig. 3 Wavelets for phase $\alpha=0, \pi / 4, \pi / 2$ and $3 \pi / 4$ 
位を生じる。この残留変位の值 $D_{\infty}$ は下式となる (付録 1 参照)。

$$
\begin{array}{ll}
D_{\infty}=\int_{-\infty}^{\infty} \int_{-\infty}^{\tau} \psi_{\alpha}(t) d t d \tau=-\frac{\pi^{2}}{2} \cos \alpha & \text { for } N=0 \\
D_{\infty}=0 & \text { for } N \geqq 1
\end{array}
$$

本ウェーブレット群は $N=0$ の場合とそれ以外で、上述した残留変 位の面だけでなく後述する二乗積分值においても特徴を異にしてお り、興味深い。

\section{3. 要素波形の抽出}

\section{1 1つのウェーブレットに対する抽出}

元の波形 $y$ に対して、ウェーブレット $\psi$ の周期および振幅を変化 させて適合する要素波形を抽出する。ウェーブレット $\psi$ の周期を $s$ 倍し、時間を $\tau$ シフトしたものを $\psi^{\text {S, }}$ とする。

$$
\psi^{s, \tau}(t)=\psi\left(\frac{t-\tau}{s}\right)
$$

これを $\lambda$ 倍したものと $y(t)$ の適合の悪さを両者の差の二乗の積分 值で評価する。

$$
\begin{gathered}
\int_{-\infty}^{\infty}\left(\lambda \psi^{s, \tau}(t)-y(t)\right)^{2} d t \\
=\lambda^{2} \int_{-\infty}^{\infty}\left|\psi^{s, \tau}(t)\right|^{2} d t-2 \lambda \int_{-\infty}^{\infty} y(t) \psi^{s, \tau}(t) d t+\int_{-\infty}^{\infty}|y(t)|^{2} d t \\
=\int_{-\infty}^{\infty}\left|\psi^{s, \tau}(t)\right|^{2} d t\left[\lambda-\frac{\int_{-\infty}^{\infty} y(t) \psi^{s, \tau}(t) d t}{\int_{-\infty}^{\infty}\left|\psi^{s, \tau}(t)\right|^{2} d t}\right]^{2} \\
+\int_{-\infty}^{\infty}|y(t)|^{2} d t-\frac{\left(\int_{-\infty}^{\infty} y(t) \psi^{s, \tau}(t) d t\right)^{2}}{\int_{-\infty}^{\infty}\left|\psi^{s, \tau}(t)\right|^{2} d t}
\end{gathered}
$$

となり、また、

$$
\begin{aligned}
& \int_{-\infty}^{\infty}|y(t)|^{2} d t=\text { constant } \\
& \int_{-\infty}^{\infty}\left|\psi^{s, \tau}(t)\right|^{2} d t=s \int_{-\infty}^{\infty}|\psi(t)|^{2} d t=s \times \text { positive constant }
\end{aligned}
$$

であることから、式(10)を最小にするためには、

$$
C(s, \tau)=\frac{1}{\sqrt{S}} \int_{-\infty}^{\infty} y(t) \psi^{s, \tau}(t) d t
$$

とする $C$ の絶対值を最大にする必要がある。式(13)は連続ウェーブ レット変換の定義式でもある。このときの解を $s=S 、 \tau=\mathrm{T}$ とすれば、 式(10)を最小にする $\lambda$ が以下の通り得られる。

$$
\lambda=\frac{\int_{-\infty}^{\infty} y(t) \psi^{s, \tau}(t) d t}{\int_{-\infty}^{\infty}\left|\psi^{s, \tau}(t)\right|^{2} d t}=\frac{C(S, \mathrm{~T})}{\sqrt{S} \int_{-\infty}^{\infty}|\psi(t)|^{2} d t}
$$

\section{2 複数のウェーブレットに対する抽出}

位相が任意、かつ、複数の $N$ に対するウェーブレット群に対し、 3.1 節と同様に差の二乗積分值が最小になるという条件で、元の波 形に最も適合する要素波形を抽出する。

位相を $\alpha$ とするウェーブレットを $\psi_{\alpha}$ とする。式(9)と同様に、

$$
\psi_{\alpha}^{s, \tau}(t)=\psi_{\alpha}\left(\frac{t-\tau}{s}\right)
$$

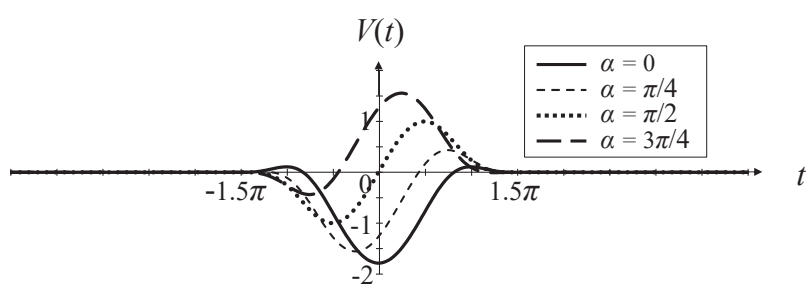

(a) $N=0$

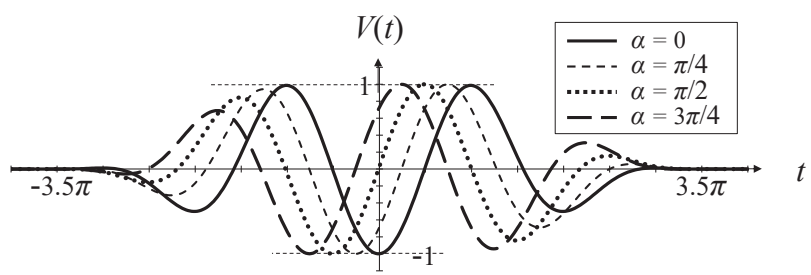

(b) $N=1$

Fig.4 Velocity waveforms of wavelets

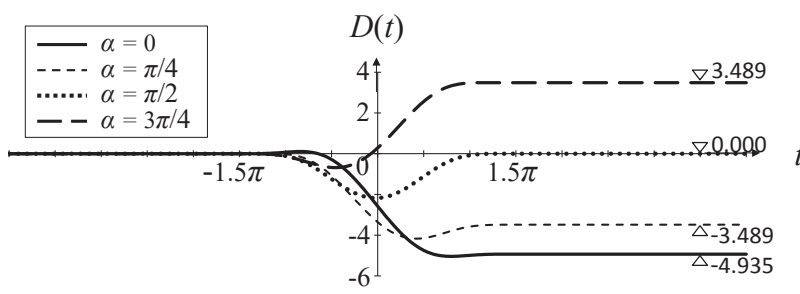

(a) $N=0$

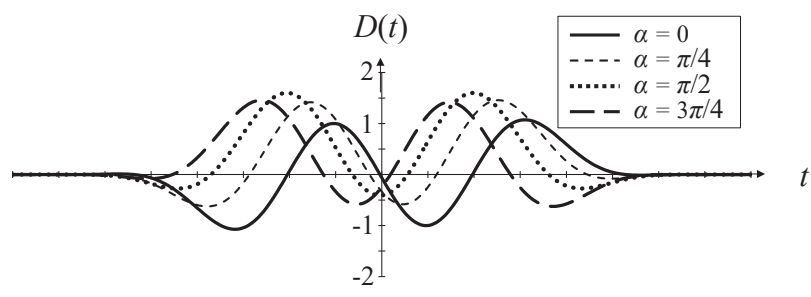

(b) $N=1$

Fig.5 Displacement waveforms of wavelets

とすれば、式(10)、(11)は同様に書ける。式(12)については、 $N \geqq 1$ の場合、ウェーブレットの二乗積分值が $\alpha$ によらず

$$
\int_{-\infty}^{\infty}\left|\psi_{\alpha}^{s, \tau}(t)\right|^{2} d t=s \times(14+12 N) \times \frac{\pi}{16}
$$

となるが、 $N=0$ の場合はウェーブレットの二乗積分值が $\alpha$ にって 異なり、

$$
\int_{-\infty}^{\infty}\left|\psi_{\alpha}^{s, \tau}(t)\right|^{2} d t=s \times(14+\cos 2 \alpha) \times \frac{\pi}{16}
$$

となる (付録 2 参照)。従って、 $y$ と $\lambda \psi_{\alpha}^{\mathrm{s}, \tau}$ の差の二乗を最小化する (以降、最適化条件) ためには、下式の絶対值を最大にすればよい。

$$
\begin{aligned}
& G_{0}(s, \tau, \alpha)=\frac{1}{\sqrt{s(14+\cos 2 \alpha)}} \int_{-\infty}^{\infty} y(t) \psi_{\alpha}^{s, \tau}(t) d t \text { for } N=0 \\
& G_{N}(s, \tau, \alpha)=\frac{1}{\sqrt{s(14+12 N)}} \int_{-\infty}^{\infty} y(t) \psi_{\alpha}^{s, \tau}(t) d t \quad \text { for } N \geqq 1 \\
& \text { さて、}
\end{aligned}
$$




$$
\int_{-\infty}^{\infty} y(t) \psi_{\alpha+\pi}^{s, \tau}(t) d t=-\int_{-\infty}^{\infty} y(t) \psi_{\alpha}^{s, \tau}(t) d t
$$

であるから、 $G_{N}\left(G_{0}\right.$ も含む) が正であるとしても一般性を失わない。 従って、最適化条件は式(18)を最大にすること、になる。

今、 $s$ および $\tau$ がある值の時に、式(18)を最大にする $\alpha$ を求める。 位相が $\alpha$ のゥーブレットは、

$$
\begin{aligned}
\psi_{\alpha}(t) & =\xi(t) \sin (t+\alpha) \\
& =\xi(t) \cos \alpha \sin (t)+\xi(t) \sin \alpha \cos (t) \\
& =\cos \alpha \psi_{\alpha=0}(t)+\sin \alpha \psi_{\alpha=\pi / 2}(t)
\end{aligned}
$$

のように、位相が 0 と $\pi / 2$ のウェーブレットで表すことができる。 $\psi^{\mathrm{s}, \tau}$ についても同様である。これらのウェーブレットに対する積分項を それぞれ下記のようにおく。

$$
\begin{aligned}
& \Psi_{0}=\int_{-\infty}^{\infty} y(t) \psi_{\alpha=0}^{s, \tau}(t) d t \\
& \Psi_{1}=\int_{-\infty}^{\infty} y(t) \psi_{\alpha=\pi / 2}^{s, \tau}(t) d t
\end{aligned}
$$

$N=0$ の場合、式(18b)より、

$$
\sqrt{s} G_{0}=\frac{\cos \alpha}{\sqrt{14+\cos 2 \alpha}} \Psi_{0}+\frac{\sin \alpha}{\sqrt{14+\cos 2 \alpha}} \Psi_{1}
$$

となり、 $14+\cos 2 \alpha=13+2 \cos ^{2} \alpha=15-2 \sin ^{2} \alpha$ であることから、

$$
\sqrt{s} \frac{d G_{0}}{d \alpha}=\frac{-13 \Psi_{0} \sin \alpha+15 \Psi_{1} \cos \alpha}{(14+\cos 2 \alpha) \sqrt{14+\cos 2 \alpha}}
$$

となる。 $\alpha$ が極值をとる条件として $d G(\alpha) / d \alpha=0$ を解けば、

$$
\tan \alpha=\frac{\sin \alpha}{\cos \alpha}=\frac{15 \Psi_{1}}{13 \Psi_{0}}
$$

すなわち、

$$
\alpha=\tan ^{-1}\left(\frac{15 \Psi_{1}}{13 \Psi_{0}}\right)
$$

このうち、最大值になるためには、

$$
\Psi_{0} \cos \alpha \geq 0, \quad \Psi_{1} \sin \alpha \geq 0
$$

であり、以下のように $\alpha$ を求めることができる。

$$
\alpha=\operatorname{angle}\left(13 \Psi_{0}+15 \Psi_{1} i\right)
$$

また、このときの最大值は下式となる。

$$
G_{0}=\frac{1}{\sqrt{s}} \sqrt{\frac{1}{15} \Psi_{0}^{2}+\frac{1}{13} \Psi_{1}^{2}}
$$

一方、 $N \geqq 1$ の場合、式(18a)より、

$$
\sqrt{s} G_{N}=\Psi_{0} \cos \alpha+\Psi_{1} \sin \alpha
$$

となり、 $N=0$ の場合と同様にして、以下のように $\alpha$ を求めることが できる。

$$
\alpha=\operatorname{angle}\left(\Psi_{0}+\Psi_{1} i\right)
$$

また、このときの最大値は、

$$
G_{N}=\frac{1}{\sqrt{S}} \sqrt{\frac{\Psi_{0}^{2}+\Psi_{1}^{2}}{14+12 N}}
$$

である。最適な振幅 $\lambda$ は $N$ にかかわらず下式の通りである。

$$
\lambda=\frac{\int_{-\infty}^{\infty} y(t) \psi_{\alpha}^{s, \tau}(t) d t}{\int_{-\infty}^{\infty}\left|\psi_{\alpha}^{s, \tau}(t)\right|^{2} d t}
$$

\section{3 抽出の流れ}

本提案手法の要素波形抽出の流れを以下にまとめる。

式(21)はシフト時間 $\tau$ に関する畳み込み積分であり、 $y$ および $\psi$ の それぞれのフーリエ変換の積として高速に算出できる。これを用い て式(28) $[N=0$ の場合］または式(31) $[N \geqq 1$ の場合 $]$ から、周期お よび $N$ がある值の時に、最適となるシフト時間を得る。そのときの 位相は式(27) $[N=0$ の場合 $]$ または式(30) $[N \geqq 1$ の場合 $]$ から得 られる。探索範囲として設定した周期および $N$ に対し、これらを繰 り返し計算し、最適となる（ $G_{N}$ を最大にする）周期および $N$ を算出 する。振幅は式(32)で得られる。

次に、以上のとおり抽出した要素波形を元の波形から引いた残差:

$$
y^{\prime}(t)=y(t)-\lambda \psi_{\alpha}^{s, \tau}(t)
$$

を新たに抽出対象 $y$ として、上述の要素波形抽出作業を繰り返す。

\section{4 ウェーブレット解析やフーリエ解析との比較}

本来、ウェーブレット解析は 1 つのウェーブレットを用いてなさ れるものであり、本提案手法のように位相 $\alpha$ や時系列フィルタの形 状を変えた複数のウェーブレットを扱わない。本手法で $N$ と $\alpha$ を固 定（1 つのウェーブレットのみ使用）すると通常のウェーブレット 解析と同様になり、 $N$ を小さい值に設定すれば局所的な（非定常的 な傾向を持つ）パルスを扱うことができる。一方、 $N$ を固定し、無 限大に漸近させると本手法はフーリエ解析に漸近する。つまり、 $N$ が大きい場合は繰り返し数の多い（定常的な傾向を持つ）波を扱う ことができる。このように本手法は非定常を扱うウェーブレット解 析と定常を扱うフーリエ解析の双方の特徵を併せ持つものであり、 波の特性に応じて非定常性の強い波も定常性の強い波もそれぞれ抽 出が可能である。

\section{4. 解析例}

1995 年の兵庫県南部地震において JR 鷹取で観測された波形 ${ }^{8)}$ の NS 成分 (以下、JR 鷹取) に本手法を適用した。周期は 0.1 秒から 10.0 秒を対数軸上で 200 分割し、第 3.3 節で述べた手順で繰り返し 要素波形を抽出した。

初めの 10 回で抽出された波形を Fig.6 に示す。Fig.6(a)、(b)、(c) はそれぞれ $N=0 、 1 、 2$ と固定した中で最適なものを抽出（以降、そ れぞれ CASE 1、2、3)、Fig.6(d)は $N<30$ において最適なものを抽出 （以降、CASE 4）した結果である。CASE1〜3 は最適な位相を抽出 している点を除いて従来のウェーブレット解析によるものと同じで あり、ほぼ従来手法と解釈することができる。図中丸番号は抽出し た順番を示す。各図の一番上には抽出した 10 波を合成した波形を示 す。いずれのケースも概ね元の波形を模擬しているが、CASE 4 が 最もよく再現できているように思われる。

これら抽出した周期、位相、振幅について Table 1 にまとめて示す。 第 2 節で述べたように、本ウェーブレットは $N=0$ の時のみ 2 階積分 
Table 1 Parameters for extracted waveforms

\begin{tabular}{|c|c|c|c|c|c|c|c|c|}
\hline & $N$ & $\begin{array}{l}\text { Period } \\
\text { (s) }\end{array}$ & $\begin{array}{c}\text { Phase } \\
(\times \pi)\end{array}$ & $\begin{array}{l}\text { Amplitude } \\
\left(\mathrm{m} / \mathrm{s}^{2}\right)\end{array}$ & $N$ & $\begin{array}{c}\text { Period } \\
\text { (s) }\end{array}$ & $\begin{array}{c}\text { Phase } \\
(\times \pi)\end{array}$ & $\begin{array}{l}\text { Amplitude } \\
\left(\mathrm{m} / \mathrm{s}^{2}\right)\end{array}$ \\
\hline & \multicolumn{4}{|c|}{ CASE $1(N=0)$} & \multicolumn{4}{|c|}{ CASE $2(N=1)$} \\
\hline (1) & 0 & 1.479 & 0.446 & 5.544 & 1 & 1.380 & -0.080 & 3.801 \\
\hline (2) & 0 & 1.549 & -0.664 & 2.876 & 1 & 1.413 & 0.970 & 2.262 \\
\hline (3) & 0 & 0.550 & 0.521 & 4.638 & 1 & 0.575 & -0.455 & 3.320 \\
\hline (4) & 0 & 1.445 & 0.512 & 2.603 & 1 & 1.288 & 0.012 & 2.199 \\
\hline (5) & 0 & 1.230 & -0.310 & 2.575 & 1 & 1.549 & 0.119 & 1.543 \\
\hline (6) & 0 & 2.138 & -0.417 & 1.428 & 1 & 0.398 & 0.530 & 2.788 \\
\hline (7) & 0 & 0.324 & 0.547 & 3.553 & 1 & 0.417 & -0.441 & 1.973 \\
\hline (8) & 0 & 0.263 & 0.225 & 3.369 & 1 & 1.698 & 0.653 & 0.891 \\
\hline (9) & 0 & 0.468 & -0.332 & 2.071 & 1 & 2.138 & 0.442 & 0.743 \\
\hline \multirow[t]{2}{*}{ (10) } & 0 & 0.776 & 0.996 & 1.513 & 1 & 0.891 & 0.739 & 1.125 \\
\hline & \multicolumn{4}{|c|}{ CASE $3(N=2)$} & \multicolumn{4}{|c|}{ CASE $4(N<30)$} \\
\hline (1) & 2 & 1.259 & 0.912 & 3.171 & 0 & 1.479 & 0.446 & 5.544 \\
\hline (2) & 2 & 1.950 & -0.974 & 2.011 & 5 & 1.349 & -0.546 & 1.417 \\
\hline (3) & 2 & 1.259 & 0.770 & 1.820 & 1 & 1.096 & 0.467 & 2.345 \\
\hline (4) & 2 & 0.562 & -0.918 & 2.377 & 1 & 0.479 & -0.941 & 3.249 \\
\hline (5) & 2 & 1.202 & 0.101 & 1.508 & 1 & 2.089 & -0.295 & 1.356 \\
\hline (6) & 2 & 0.380 & 0.556 & 2.467 & 2 & 0.389 & 0.670 & 2.534 \\
\hline (7) & 2 & 0.851 & -0.782 & 1.450 & 6 & 1.072 & 0.685 & 0.932 \\
\hline (8) & 2 & 0.447 & 0.749 & 1.726 & 3 & 0.447 & 0.300 & 1.600 \\
\hline (9) & 2 & 0.389 & 0.515 & 1.736 & 12 & 0.200 & 0.106 & 1.079 \\
\hline (10) & 2 & 0.204 & 0.208 & 1.959 & 2 & 0.457 & -0.549 & 1.297 \\
\hline
\end{tabular}

が 0 にならず $(\cos \alpha=0$ の場合を除く)、残留変位を生じる。CASE 4 において 10 波の内、第 1 回目に抽出した要素波形のみが $N=0$ であ ることは興味深い。この区間で生じる残留変位が支配的である可能 性を示す。残留変位の量は式(8)で与えられるが、これは周期 $2 \pi$ 、振 幅 1 のウェーブレット $\psi_{\alpha}$ に対する值であり、周期が $T$ の場合は $[\mathrm{T} /(2 \pi)]^{2}$ 倍になる。すなわち、

$$
D_{\infty}=\int_{-\infty}^{\infty} \int_{-\infty}^{\tau} \psi_{\alpha}^{T /(2 \pi), \tau}(t) d t d \tau=-\frac{T^{2}}{8} \cos \alpha
$$

上式に Table 1 の值を代入することで、 $\left|D_{\infty}\right|=5.544 \times 1.479^{2} / 8$ $\times \cos (0.446 \pi)=0.256 \mathrm{~m}$ と残留変位が得られる。

要素波形の抽出を 50 回繰り返し、式(33)に示寸残差の二乗和（離 散時間に関する和）を元の波形の二乗和で基準化し、その推移を CASE 1〜4 に対して調べた結果を Fig.7 に示す。CASE 1〜3 の比較 において、本地震動波形に対しては、1 波のみの抽出では CASE 1 やCASE 2 が良い近似を与えるが、波の数が増えると差は近づき、 抽出回数が 6 以上では CASE 3 が良い近似を与える。なお、CASE 4 は図示の範囲において常に最良值を示すことが分かる。

定常的な波に対する適用性を調べるために正弦波の振動数を掃引 した波形（以下スイープ波）に対して本手法を適用する。用いたス イープ波（Fig.9(b)参照）は 40 秒間のデータとした。振動数 $0.2 \mathrm{~Hz}$ で始まり、時刻 1 秒から 39 秒までの 38 秒間で $0.2 \mathrm{~Hz}$ から $2.0 \mathrm{~Hz}$ へ 連続的かつ一定に振動数を増加させ、 39 秒以降は $2.0 \mathrm{~Hz}$ を維持させ たものである。時刻 0 秒から 1 秒にかけて $0 \rightarrow 1$ 倍と定率で増加寸る 時系列フィルタ、時刻 39 秒から 40 秒にかけて $1 \rightarrow 0$ 倍と定率で減少 する時系列フィルタをそれぞれかけている。

要素波形の抽出を 50 回繰り返し、式(33)に示寸残差の二乗和（離

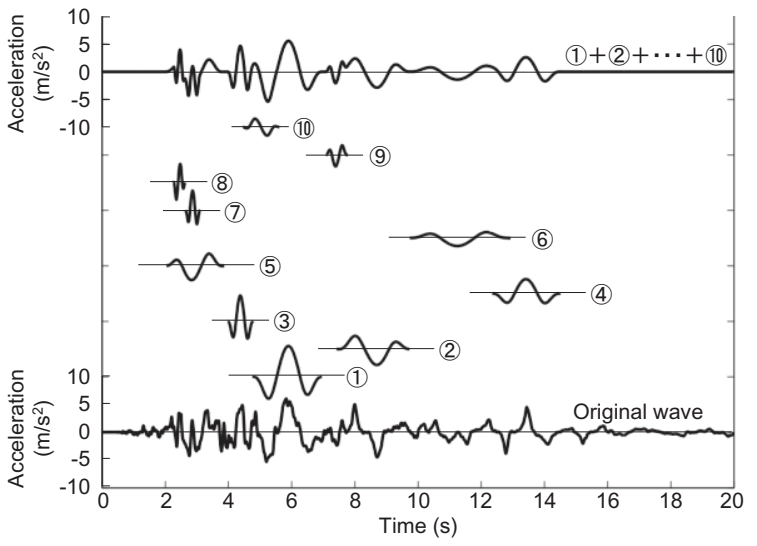

(a) CASE $1(N=0)$

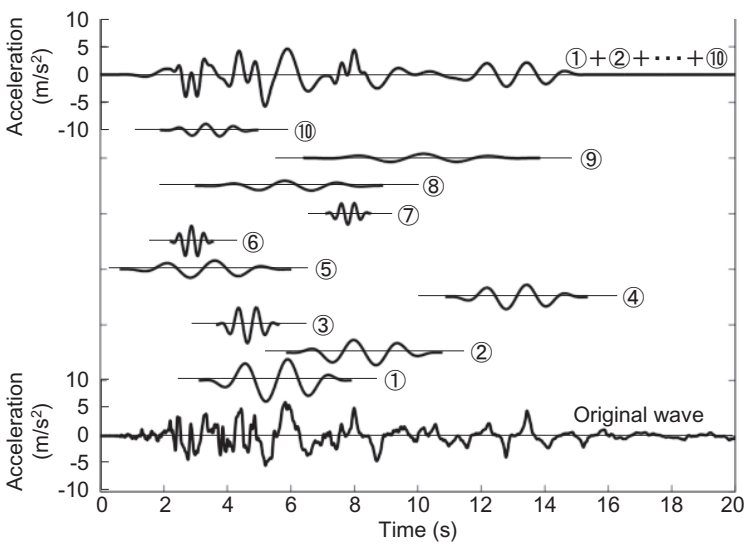

(b) CASE $2(N=1)$

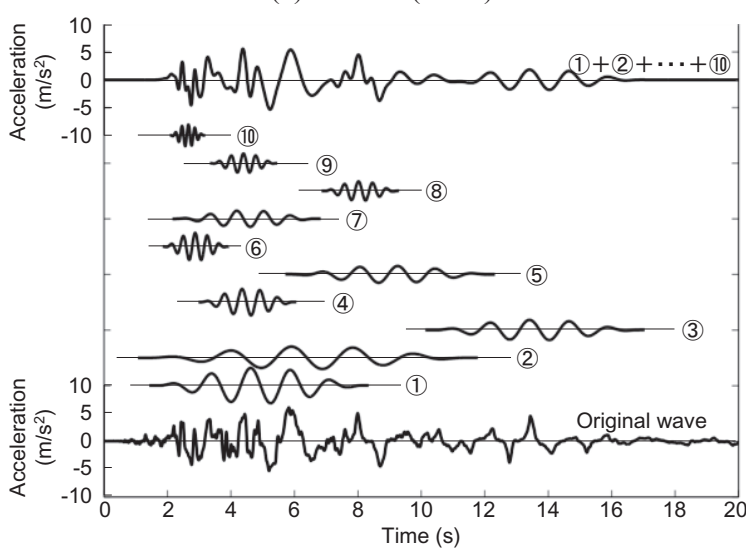

(c) CASE $3(N=2)$

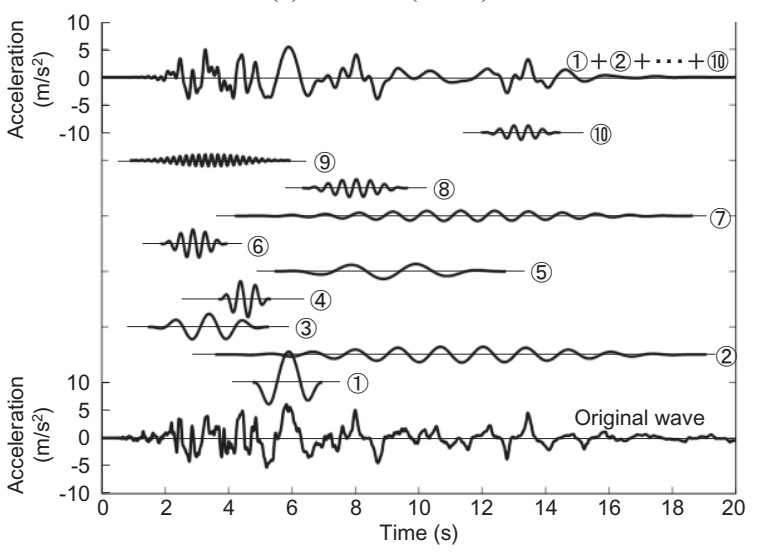

(d) CASE $4(N<30)$

Fig.6 Extracted waveforms 


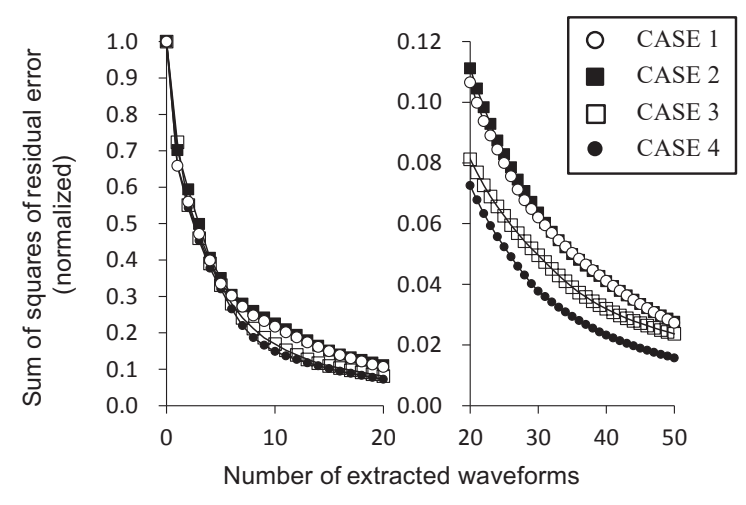

Fig.7 Transition of error against extracted number (JR Takatori)

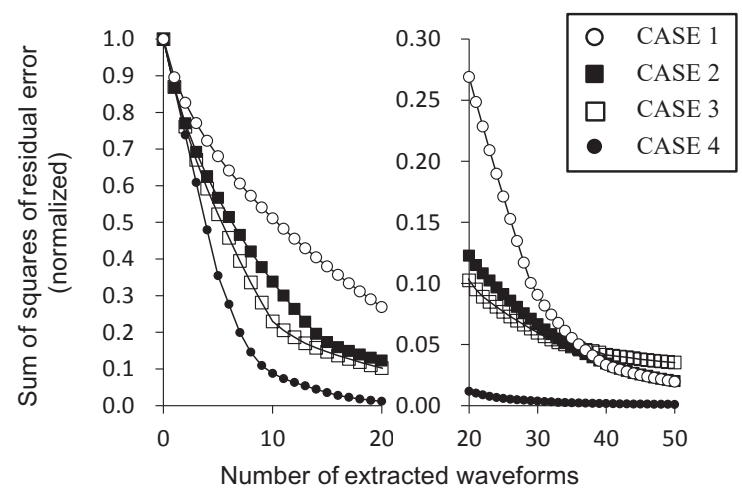

Fig.8 Transition of error against extracted number (sweep wave)

散時間に関する和）を元の波形の二乗和で基準化し、その推移を CASE 1〜4 に対して調べた結果を Fig.8 に示寸。CASE 1〜3の比較 において、抽出回数が 34 までは CASE $3 \rightarrow 2 \rightarrow 1$ の順に良い近似を与 える。この傾向は JR 鷹取の結果（Fig.7）と異なる。定常に近い波 に対しては小さい $N$ では効率よく（抽出回数を少なくして）精度を 上げることができないことを示している。抽出回数が 39 以上になる と CASE1 が CASE 2、3 よりも良い近似を与える。スイープ波は明 瞭な 42 波で構成されており、抽出回数が構成波数と同等程度あれば、 1 波ずつ抽出する方（CASE1）が、2、3 波同時に抽出する（CASE2、 3）よりも精度が高くなるのだと思われる。JR 鷹取の結果と同様、 CASE 4 は常に最良值を示すが、CASE 4 の CASE 1 に対する優位性 は JR 鷹取に比べてスイープ波の方が高い。これも、JR 鷹取が非定 常的、スイープ波が定常的であることと関係していると思われる。

抽出結果を概観するために、各時間における抽出された波を各振 動数に対してプロットした。CASE 4 における 50 波抽出に対する結 果をJR 鷹取およびスイープ波について Fig.9 に示す。図中凡例に示 寸ように大きい振幅 $\lambda^{\prime}$ ( = $\lambda$ /原波形の最大振幅) の波の線を太くし ている。JR 鷹取は、概ね主要動部に対応する時刻 10 秒までの区間 では継続時間の短く振幅の大きい波が抽出されている。時刻 6 秒付 近には $N=0$ のパルス状の波、それに先行してやや繰り返し数の多い $N=1,2$ の波が $0.91,2.09,2.57 \mathrm{~Hz}$ にそれぞれ抽出されている。主要動 に続く後続波部においてはやや振幅は小さいが継続時間の長い波が $0.3 \sim 1.0 \mathrm{~Hz}$ を中心に抽出されており、これらは主に地盤の影響を反 映した成分に対応すると考えられる。

スイープ波に対する結果である Fig.9(b)には、各時刻においてス イープ波に設定した振動数を丸点線でプロットした。抽出された波

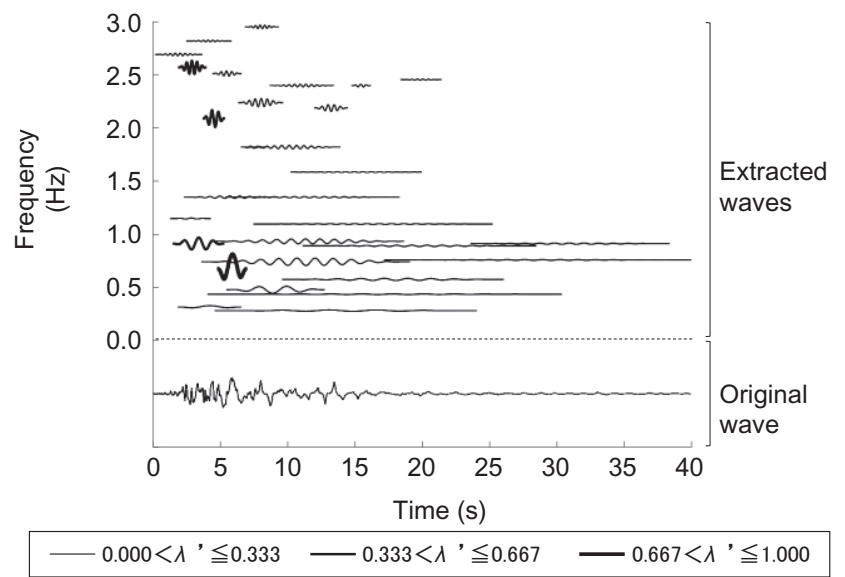

(a) JRTakatori

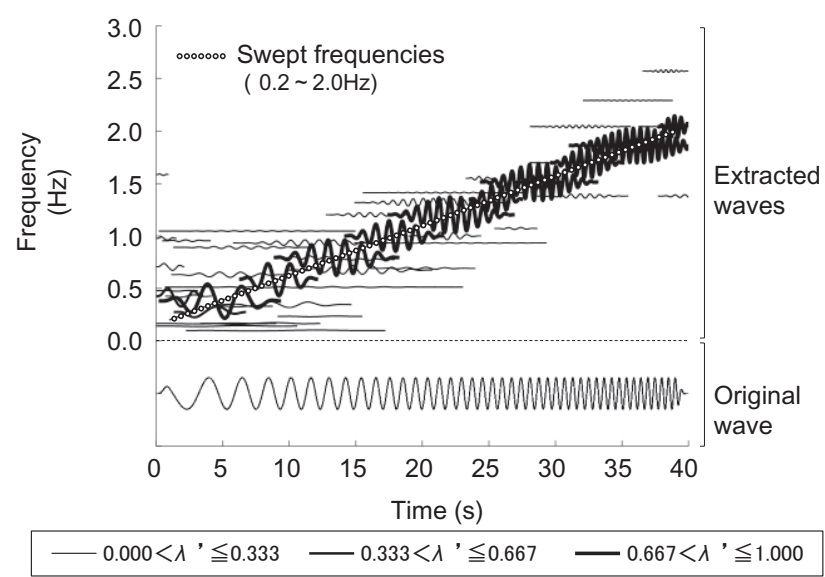

(b) Sweep wave

Fig.9 Extracted waveforms plotted with their frequencies

はこの振動数によく対応している。この振動数を外れた場所にも振 幅の小さい波が抽出されている。他の手法でも同様であるが本手法 も特定の波形(ウェーブレット)に適合するよう抽出しているため、 その残差としてこれらの波形が発生する。主要成分以外の残差とし て抽出された要素波形も原波形を構成する成分ではあるが波形解析 の観点からは誤差と把えることもできる。

5. まとめ

地震動波形を単純化する手法として、正弦波パルスの抽出による 手法を提案した。本手法は定常状態で有効なフーリエ変換と非定常 状態で有効なウェーブレット変換の特徵を併せ持つ抽出法である。 また、従来のウェーブレット変換による抽出法と比較して、パルス の周期、振幅の意味づけが明確であり、位相も任意に設定すること ができる。

本手法を 1995 年兵庫県南部地震の JR 鷹取での観測データおよび スイープ波に適用しその近似精度を確認した。非定常的な JR 鷹取、 定常的なスイープ波ともにそれぞれの特性に応じた波が適宜抽出さ れた。特に、スイープ波のように定常的な特性が含まれる場合は、 従来のウェーブレット変換のような短いパルスで抽出するよりも残 差の二乗和を小さくすることができる。

本手法により客観的規準に基づいて地震動波形を周期、振幅、位 相、継続時間が異なる要素波形に分割することが可能になる。複数 記録から構造物に影響が大きいと考えられる特性を有する要素波形 
を抽出し、震源、伝播経路、地盤特性の影響について検討すること で、設計用入力地震動の作成に資する新たな知見が得られる可能性 がある。

また、本手法は信号を少ない情報量で近似再現する手法であり、 地震動波形だけでなく、音声や画像の圧縮技術としても応用が期待 できる。

\section{謝辞}

JR 西日本鷹取駅構内地盤上における 1995 年兵庫県南部地震の記録 を検討に用いました。

\section{参考文献}

1) J. W. Baker: Quantitative Classification of Near-Fault Ground Motions Using Wavelet Analysis, Bulletin of the Seismological Society of America, Vol. 97, No.5, pp.1486-1501, 2007.10

2) M. F. Vassiliou and N. Makris: Estimating Time Scales and Length Scales in Pulselike Earthquake Acceleration Records with Wavelet Analysis, Bulletin of the Seismological Society of America, Vol. 101, No.2, pp.596-618, 2011.4

3) 小山哲央, 永野正行: パルス状の地震波の単純化と弾塑性応答特性に関寸 る基礎的研究, 2010 年度日本建築学会関東支部研究報告集, pp. 253-256, 2011.3

4) 安本宏, 岡沢理映, 多幾山法子, 大西良広, 林康裕 : パルス性地震動に対 する免震建物の擁壁衝突時の最大応答評価, 日本建築学会構造系論文集, 697 号, pp.385-392, 2014.3

5) 木村友香, 岡沢理映, 関口春子, 林康裕: 大阪市域を対象としたパルス性 地震動に対寸る超高層建物群の被害予測, 平成 26 年度日本建築学会近畿支 部研究報告集, pp.113-116, 2014.5

6) K. Kojima and I. Takewaki: Critical earthquake response of elastic-plastic structures under near-fault ground motions (Part 1: Fling-step input), Frontiers in Built Environment, Vol.1, No.12, 2015.7

7) 野津厚, 山田雅行, 長尾毅, 入倉孝次郎: 海溝型巨大地震における強震動 パルスの生成とその生成域のスケーリング, 日本地震工学会論文集, 第 12 巻, 第 4 号（特集号），pp.209-228, 2012.9

8) 中村豊, 上半文昭, 井上英司 : 1995 年兵庫県南部地震の地震動記録波形と 分析(II), JR 地震情報 No.23d, 財団法人鉄道総合技術研究所ユレダス開発 推進部, 1996.3

\section{付録 1 式(8a)および式 (8b)の誘導}

ウェーブレット $\psi_{\alpha}$ の 1 階積分を $z$ とする。

$$
z(\tau)=\int_{-\infty}^{\tau} \psi_{\alpha}(t) d t=\int_{-\infty}^{\tau} \xi(t) \sin (t+\alpha) d t
$$

式(2)および式(7)より、-( $2 N+3 / 2) \pi \leqq t \leqq-\pi / 2$ において、 $t_{1}=t+\pi / 2$ として、

$$
\begin{aligned}
& z(t)=\int_{-(2 N+1) \pi}^{t_{1}} \zeta(-\tau) \sin (\tau+\alpha-\pi / 2) d \tau \\
& \quad=-\int_{-(2 N+1) \pi}^{t_{1}}\left(\cos \left(\frac{-\tau}{2 N+1}\right)+1\right) / 2 \times \cos (\tau+\alpha) d \tau \\
& =-\frac{1}{4} \int_{-(2 N+1) \pi}^{t_{1}}\left\{\cos \left(\frac{2 N+2}{2 N+1} \tau+\alpha\right)+\cos \left(\frac{2 N}{2 N+1} \tau+\alpha\right)+2 \cos (\tau+\alpha)\right\} d \tau \\
& =-\frac{1}{4}\left[\frac{2 N+1}{2 N+2}\left\{\sin \left(\frac{2 N+2}{2 N+1} t_{1}+\alpha\right)-\sin \alpha\right\}+I_{1}+2 \sin \left(t_{1}+\alpha\right)+2 \sin \alpha\right]
\end{aligned}
$$

ここで、

$$
\begin{array}{ll}
I_{1}=\left(t_{1}+\pi\right) \cos \alpha & \text { for } N=0 \\
I_{1}=\frac{2 N+1}{2 N}\left\{\sin \left(\frac{2 N}{2 N+1} t_{1}+\alpha\right)-\sin \alpha\right\} & \text { for } N \geqq 1
\end{array}
$$

特に、 $t=-\pi / 2$ のときの $z$ の值 $z_{1}$ は、 $t_{l}=t+\pi / 2=0$ なので、

$$
\begin{array}{ll}
z_{1}=-(\pi / 4) \cos \alpha-\sin \alpha & \text { for } N=0 \\
z_{1}=-\sin \alpha & \text { for } N \geqq 1
\end{array}
$$

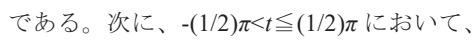

$$
z(t)=z_{1}+\int_{-\pi / 2}^{t} \sin (\tau+\alpha) d \tau=-\cos (t+\alpha)+\sin \alpha+z_{1}
$$

特に、 $t=\pi / 2$ のときの $z$ の值 $z_{2}$ は、

$$
z_{2}=-\cos (\pi / 2+\alpha)+\sin \alpha+z_{1}=2 \sin \alpha+z_{1}
$$

である。更に、 $(1 / 2) \pi<t \leqq(2 N+3 / 2) \pi$ において、式(A2)同様、 $t_{2}=t-\pi / 2$ として、 $z(t)=\frac{1}{4}\left[\frac{2 N+1}{2 N+2}\left\{\sin \left(\frac{2 N+2}{2 N+1} t_{2}+\alpha\right)-\sin \alpha\right\}+I_{2}+2 \sin \left(t_{2}+\alpha\right)-2 \sin \alpha\right]+z_{2}$

ここで、

$$
\begin{array}{ll}
I_{2}=t_{2} \cos \alpha & \text { for } N=0 \\
I_{2}=\frac{2 N+1}{2 N}\left\{\sin \left(\frac{2 N}{2 N+1} t_{2}+\alpha\right)-\sin \alpha\right\} & \text { for } N \geqq 1
\end{array}
$$

なお、 $(2 N+3 / 2) \pi<|t|$ において、 $z(t)=0$ である。

以上で $t$ の全区間において $z$ が得られた。この $z$ を $t$ に関して全区間で積分 すれば $D_{\infty}$ が得られる。

$$
\begin{gathered}
D_{\infty}=\int_{-\infty}^{\infty} z(t) d t=\int_{-(2 N+1) \pi}^{0} z\left(t_{1}-\pi / 2\right) d t_{1}+\int_{-\pi / 2}^{\pi / 2} z(t) d t+\int_{0}^{(2 N+1) \pi} z\left(t_{2}+\pi / 2\right) d t_{2} \\
=\left[\frac{1}{4}\left\{\frac{(2 N+1)^{2}}{2 N+2} \pi \sin \alpha-I_{3}+4 \cos \alpha-2(2 N+1) \pi \sin \alpha\right\}\right] \\
+\left[-2 \cos \alpha+\pi \sin \alpha+\pi z_{1}\right] \\
+\left[\frac{1}{4}\left\{-\frac{(2 N+1)^{2}}{2 N+2} \pi \sin \alpha+I_{3}+4 \cos \alpha-2(2 N+1) \pi \sin \alpha\right\}+(2 N+1) \pi z_{2}\right] \\
=(2 N+2) \pi\left(\sin \alpha+z_{1}\right)
\end{gathered}
$$

従って、式(8a)および式(8b)を得る。なお、 $I_{3}$ は式(A9)では最終的に消える が、以下である。

$$
\begin{array}{ll}
I_{3}=\left(\pi^{2} / 2\right) \cos \alpha & \text { for } N=0 \\
I_{3}=-\frac{(2 N+1)^{2}}{2 N} \pi \sin \alpha & \text { for } N \geqq 1
\end{array}
$$

\section{付録 2 式(16)および(17)の誘導}

ウェーブレット $\psi_{\alpha}$ の二乗積分值を求める。付録 1 同様、 $t_{1} 、 t_{2}$ を用いると、

$$
\int_{-\infty}^{\infty}\left|\psi_{\alpha}(t)\right|^{2} d t=\int_{-(2 N+1) \pi}^{0} \zeta^{2}\left(-t_{1}\right) \sin ^{2}\left(t_{1}+\alpha-\pi / 2\right) d t_{1}
$$$$
+\int_{-\pi / 2}^{\pi / 2} \sin ^{2}(t+\alpha) d t+\int_{0}^{(2 N+1) \pi} \zeta^{2}\left(t_{2}\right) \sin ^{2}\left(t_{2}+\alpha+\pi / 2\right) d t_{2}
$$

$=\pi / 2+\int_{0}^{(2 N+1) \pi} \zeta^{2}(t)\left\{\sin ^{2}(t+\alpha+\pi / 2)+\sin ^{2}(-t+\alpha+\pi / 2)\right\} d t$

$=\pi / 2+\frac{1}{4} \int_{0}^{(2 N+1) \pi}\left\{\cos \frac{1}{2 N+1} t+1\right\}^{2}\left\{\cos ^{2}(t+\alpha)+\cos ^{2}(t-\alpha)\right\} d t$

$$
=\pi / 2+\frac{1}{8} \int_{0}^{(2 N+1) \pi}\left(\cos \frac{2}{2 N+1} t+4 \cos \frac{1}{2 N+1} t+3\right)(\cos 2 \alpha \cdot \cos 2 t+1) d t
$$

ここで、

$$
\begin{gathered}
\int_{0}^{(2 N+1) \pi} \cos \frac{2}{2 N}+1 \cdot \cos 2 t d t=\frac{1}{2} \int_{0}^{(2 N+1) \pi}\left\{\cos \left(\frac{2}{2 N+1} t+2 t\right)+\cos \left(\frac{2}{2 N+1} t-2 t\right)\right\} d t \\
=\frac{1}{2} \int_{0}^{(2 N+1) \pi} \cos \left(\frac{4 N+4}{2 N+1} t\right) d t+\frac{1}{2} \int_{0}^{(2 N+1) \pi} \cos \left(\frac{-4 N}{2 N+1} t\right) d t \\
=\frac{1}{2} \int_{0}^{(2 N+1) \pi} \cos \left(\frac{4 N}{2 N+1} t\right) d t
\end{gathered}
$$

すなわち、式(A12)は $N=0$ のとき $\pi / 2 、 N \geqq 1$ のとき 0 となる。また、

$$
\begin{aligned}
& \int_{0}^{(2 N+1) \pi} \cos \frac{2}{2 N+1} t d t=0 \\
& \int_{0}^{(2 N+1) \pi} \cos \frac{1}{2 N+1} t \cdot \cos 2 t d t=0 \\
& \int_{0}^{(2 N+1) \pi} \cos 2 t d t=0 \\
& \int_{0}^{(2 N+1) \pi} 1 d t=(2 N+1) \pi
\end{aligned}
$$

であるから、式(A11)を展開した上でそれぞれの項に上式を適用し、更に、

$$
\int_{-\infty}^{\infty}\left|\psi_{\alpha}^{s, \tau}(t)\right|^{2} d t=s \int_{-\infty}^{\infty}\left|\psi_{\alpha}(t)\right|^{2} d t
$$

であることを考慮すれば、式(16)および式(17)を得る。 


\title{
EXTRACTION METHOD OF SINUSOIDAL WAVES FROM EARTHQUAKE GROUND MOTION TO SIMPLIFY THE MOTION
}

\author{
Masashi YAMAMOTO*, Yoshiyuki SATO** and Shusaku INOUE*** \\ * General Manager, Research and Development Institute, Takenaka Corporation, Dr.Eng. \\ ** Group Leader, Research and Development Institute, Takenaka Corporation, M.Sc. \\ *** Chief Researcher, Research and Development Institute, Takenaka Corporation, Dr.Eng.
}

Simplification of earthquake ground motion using pulse waves has been studied to observe pulse-like ground motion. These simplified pulse waves have been utilized in studies of seismic isolated and tall buildings. Simplification of observed waveforms can also be utilized to identify a source model from a series of observed ground motions. Thus, establishing a simplification method is important. Most existing methods are based on extraction of waveforms by wavelet analysis. However, these methods have two main limitations: (i) they focus on non-stationary components; hence, stationary components are not extracted, and (ii) a wavelet for extraction does not have a well-defined period and amplitude, and does have a constant phase.

First, the proposed method was formulated. In order to solve problem (i), the method extracts waveforms using multiple wavelets, as opposed to existing methods that use only one wavelet; for solving problem (ii), the wavelet is defined as the product of a sinusoidal waveform and a time-domain filter. The filter passes through a central region to clarify the definition of both period and amplitude. The shape of the filter is defined and can be changed using a non-negative integer, $N$. The proposed method selects and extracts optimum waveforms that minimize the sum of the squares of error using multiple wavelets that have arbitrary phase a and various $N$. When $N$ has a small value, and $\alpha$ is a constant, the proposed method coincides with typical wavelet analysis. Then, the method extracts a local and non-stationary waveform. When $N$ asymptotically approaches infinity, the method asymptotically approaches Fourier analysis. Then, the method extracts a repeat-cycled and stationary waveform. The method, therefore, can extract an appropriate waveform depending on the original waveform.

The proposed method was applied on an acceleration waveform observed at Japan Railway Takatori station during the Kobe earthquake in 1995. Analytical cases 1, 2, and 3 used wavelets with $N=0$, 1, and 2, respectively. Analytical case 4 used all wavelets with $N$ less than 30 . After extracting the optimum waveform, the remaining waveforms were repeatedly extracted 50 times. Comparison of the synthesized waveforms of the first 10 extracted waveforms for cases 1-4 showed that the original waveform was best reproduced by case 4 . Among the proposed wavelets, residual displacement was observed only for $N=0$. Only the first of the first 10 waveforms was extracted with $N=0$. This implies that residual displacement primarily occurred in the region of the first extracted waveform. The transition of error against the extracted number shows that cases 1 and 2 were better than case 3 initially; however, case 3 was better than cases 1 and 2 when the number exceeded five. Case 4 was the best for any extracted number. The method was also applied to a frequency-swept sinusoidal waveform. The transition of error against the extracted number showed that cases 3,2,1 were good, in this order, for numbers less than 35. Wavelets with a small $N$ value could not efficiently extract from a stationary waveform. Again, case 4 was the best for any extracted number. The advantage of case 4 over case 1 was larger for this waveform than that for the above earthquake waveforms. The frequencies of the extracted waveforms agreed well with those of the original waveform.

The proposed method extracts essential waveforms from earthquake ground motion. Thus, this method can be utilized to resolve a waveform into various waveform components caused by different propagation paths. Moreover, because this method can reproduce a waveform with a small number of parameters, it can be applied as a compression technique for sound and image. 